\title{
Văn hóa quốc gia của tổng giám đốc điều hành (CEO) và rủi ro phá sản ngân hàng: Bằng chứng ở các nước đang phát triển \\ The national culture of chief executive director (CEO) and bank- risk taking: Evidence in developing countries
}

\author{
Lương Duy Quang ${ }^{1 *}$ \\ ${ }^{1}$ Trung tâm Nghiên cứu Phát triển trường Đại học Mở Thành phố Hồ Chí Minh, Việt Nam \\ *Tác giả liên hệ, Email: quang.ld@ou.edu.vn
}

THÔNG TIN

DOI: $10.46223 /$ HCMCOUJS. econ.vi.16.1.1385.2021

Ngày nhận: 21/03/2020

Ngày nhận lại: 13/05/2020

Duyệt đăng: 14/05/2020

Tù khóa:

rủi ro ngân hàng, văn hóa quốc gia, nước đang phát triển
TÓM TẮT
Văn hóa quốc gia đang thu hút sự chú ý của các học giả, đặc biệt là trong lĩnh vực tài chính, vì nhiều nghiên cứu gần đây đã khẳng định vai trò quan trọng của văn hóa đối với sự ổn định của hệ thống ngân hàng. Nghiên cứu này điều tra mối liên hệ giữa các giá trị văn hóa quốc gia của $\mathrm{CEO}$ và rủi ro phá sản ngân hàng. Sử dụng bộ dữ liệu bảng không cân bằng với thông tin về văn hóa quốc gia của $395 \mathrm{CEO}$ làm việc cho 237 ngân hàng thương mại ở 21 quốc gia đang phát triển trong khoảng thời gian từ 2011 đến 2017 , kết quả cho thấy rủi ro ngân hàng giảm với $\mathrm{CEO}$ có chỉ số văn hóa cá nhân cao trong khi đó các CEO có khoảng cách quyền lực cao lại có xu hướng gia tăng rủi ro ngân hàng.

\section{ABSTRACT}

National culture is attracting the attention of scholars, particularly in the financial field, as many recent studies have confirmed the critical role of culture in the stability of the banking system. In this paper, we investigate the link between CEO's national cultural values and bank risk-taking. Using an unbalanced panel dataset which contains national cultural values of 395 CEOs who work for 237 commercial banks in 21 countries over the period 2011-2017, we find that bank risk-taking is negatively associated with CEOs who score high in the individualistic cultural dimension. Also, we see that bank risk tends to increase under the management of high power distance CEOs.
\end{abstract}

Keywords:

bank-risk taking, national culture, and developing countries

\section{Giới thiệu}

Văn hóa là yếu tố cơ bản góp phần vào quá trình hình thành thể chế xã hội và hành vi con người trong nền kinh tế. Theo Hofstede, Hofstede, và Minkow (2010), văn hóa là hệ thống giá trị, niềm tin tồn tại trong tâm trí con người và được thể hiện ở nhiều hình thức khác nhau như ngôn ngữ, biểu tượng, nghi lễ. Trong khoảng hai thập kỷ trở lại đây, ngày càng có nhiều học giả quan tâm đến vai trò của văn hóa trong việc giải thích các vấn đề kinh tế, xã hội như văn hóa và cấu trúc thị trường tài chính (Kwok \& Tadesse, 2006), văn hóa và tham nhũng (Boateng, Wang, Ntim, \& Glaister, 2020; Zheng, 2012), vốn xã hội (López \& Santos, 2014) và chính sách chi trả cổ tức (Shao, Kwok, \& Guedhami, 2010). 
Trong lĩnh vực nghiên cứu về rủi ro phá sản ngân hàng, một xu hướng tương tự cũng xảy ra khi ngày càng có nhiều học giả nhấn mạnh văn hóa như là một yếu tố quan trọng để giải thích mức độ rủi ro của các ngân hàng. Có thể chia các nghiên cứu trong định hướng nghiên cứu này thành ba nhóm (1) nhóm nghiên cứu tập trung vào mối quan hệ giữa văn hóa quốc gia và rủi ro phá sản ngân hàng (Ashraf, Zheng, \& Arshad, 2016; Bussoli, 2017; Kanagaretnam, Lim, \& Lobo, 2013; Mourouzidou-Damtsa, Milidonis, \& Stathopoulos, 2017), (2) nhóm phân tích tác động của văn hóa ở cấp độ doanh nghiệp (Mervelskemper, Möller, \& Schumacher, 2018; Nguyen, Nguyen, \& Sila, 2018) và (3) nhóm văn hóa ở cấp độ cá nhân (Bushman, Davidson, Dey, \& Smith, 2015). Cách phân chia này cho thấy mối quan hệ giữa văn hóa cá nhân (ví dụ như văn hóa của CEO) và rủi ro ngân hàng chưa được trả lời một cách thỏa đáng cả về mặt lý thuyết lẫn thực nghiệm. Nhiều nghiên cứu chỉ rằng hành vi của $\mathrm{CEO}$ sẽ tác động rất lớn đến văn hóa của tổ chức (Nilsen, 2016; O'Reilly, Caldwell, Chatman, \& Doerr, 2014). Do đó, có cơ sở để tin rằng văn hóa của $\mathrm{CEO}$ sẽ ảnh hưởng đến mức độ rủi ro mà ngân hàng chấp nhận. Điều này đặt ra một câu hỏi chưa được các nghiên cứu thực nghiệm giải đáp là: "Văn hóa quốc gia của $\mathrm{CEO}$ có quan hệ như thế nào với rủi ro ngân hàng?”.

\section{Văn hóa và rủi ro ngân hàng}

Trong phần này, mối quan hệ giữa văn hóa quốc gia và hành vi chấp nhận rủi ro của CEO sẽ được thảo luận. Nghiên cứu này sử dụng 3 chiều văn hóa được phát triển bởi Giáo sư Hofstede (Hofstede, 2001; Hofstede et al., 2010) như một công cụ để quan sát ảnh hưởng của văn hóa đến rủi ro ngân hàng.

\subsection{Chủ nghĩa cá nhân và chủ nghĩa tập thể (Individualism and Collectivism)}

Chủ nghĩa cá nhân/chủ nghĩa tập thể là khái niệm liên quan đến kỳ vọng mà một người sẽ hành xử theo lợi ích cá nhân hay tập thể. Ở chiều cá nhân của văn hóa, mọi người có xu hướng nhấn mạnh lợi ích cá nhân lên trên lợi ích nhóm. Hofstede và cộng sự (2010) cho thấy những đứa trẻ sống trong văn hóa cá nhân thường định nghĩa bản thân bằng chữ "tôi” thay vì là chữ "chúng ta". Những đứa trẻ này lựa chọn bạn chơi dựa trên quan điểm cá nhân và được giáo dục để có thể tự lập thay vì sống nhờ cha mẹ. Trong khi đó, người theo chủ nghĩa tập thể định nghĩa bản thân mình là một phần của mạng lưới quan hệ xã hội thay vì một cá thể độc lập (Markus \& Kitayama, 1991). Khi có xung đột lợi ích giữa cá nhân và tập thể thì người theo chủ nghĩa tập thể có xu hướng hành xử theo lợi ích của tập thể hơn cá nhân (Hofstede et al., 2010). Một nghiên cứu về tâm lý xã hội gần đây của Shupp và Williams (2008) chỉ ra rằng những quyết định của nhóm nhỏ có xu hướng an toàn hơn quyết định của cá nhân trong các tình huống có rủi ro cao. Ngoài ra, Hofstede và Hofstede (2005) cũng cho thấy rằng tính độc lập, tự định hướng và chú trọng thành tích cá nhân là những nét đặc trưng ở xã hội theo văn hóa cá nhân. Vì vậy, trong bối cảnh của ngân hàng, $\mathrm{CEO}$ theo chủ nghĩa cá nhân được dự đoán là sẽ mang nhiều rủi ro hơn cho ngân hàng so với CEO theo chủ nghĩa tập thể.

H1: Mức độ chủ nghĩa cá nhân trong văn hóa quốc gia của CEO càng cao, mức độ rủi ro phá sản ngân hàng càng cao

\subsection{Hạn chế không chắc chắn (Uncertainty avoidance)}

Hạn chế không chắc chắn đề cập tới mức độ mà các thành viên của một nền văn hóa cảm thấy khó khăn và không thoải mái với tương lai bất định. Hofstede (1983) cho thấy những người không ưa thích sự không chắc chắn cảm thấy bị đe dọa và lo lắng đối với những tình huống không rõ ràng hoặc không chắc chắn, do đó, họ mong muốn tìm kiếm sự ổn định để bảo vệ cuộc sống của chính họ. Theo Hofstede và Hofstede (2005), đặc điểm văn hóa này dẫn đến nhu cầu là cần có 
những quy tắc, những quy định trong xã hội để có thể đảm bảo kết quả có thể dự đoán được. Trong những xã hội như vậy, hoạt động của các chủ thể có xu hướng được cấu trúc chặt chẽ, hệ thống nhằm giảm thiểu rủi ro và tránh sự tham vọng (Pillay \& Dorasamy, 2010). Ngược lại, ở những nền văn hóa không quá khắt khe với sự không chắc chắn, các thành viên thường thoải mái hơn với tình huống không lường trước được và dễ dàng chấp nhận rủi ro hơn. Thậm chí, họ biểu hiện cảm xúc không thân thiện với những quy tắc của xã hội và tin rằng những quy tắc này chỉ được áp dụng trong những tình huống thật sự cần thiết (Hofstede et al., 2010). Vì vậy, chúng tôi lập luận rằng văn hóa không ưa thích sự không chắc chắn có mối quan hệ nghịch biến với rủi ro phá sản ngân hàng.

H2: Mức độ không chắc chắn trong văn hóa quốc gia của CEO càng cao, mức độ rủi ro phá sản ngân hàng càng thấp

\subsection{Khoảng cách quyền lục (Power distance)}

Khoảng cách quyền lực là mức độ mà các thành viên có ít ảnh hưởng hơn trong một tổ chức xã hội (gia đình, trường học, cơ quan) kỳ vọng và chấp nhận rằng quyền lực sẽ không được chia sẻ một cách công bằng (Hofstede et al., 2010). Trong một xã hội có khoảng cách quyền lực lớn, những thành viên có ít quyền lực được kỳ vọng sẽ thể hiện sự tôn trọng đối với những người có nhiều quyền lực hơn. Ví dụ, trẻ em phải nghe lời cha mẹ và thầy cô giáo. Trong môi trường làm việc, văn hóa khoảng cách quyền lực cũng đòi hỏi cấp dưới phải kính trọng và giữ "khoảng cách" với cấp trên của họ. Trong những nền văn hóa như vậy, quyền lực của tổ chức chỉ tập trung ở một vài người. Làm theo những yêu cầu của cấp trên là quan trọng hàng đầu và chính sách phúc lợi cũng thể hiện sự không công bằng giữa cán bộ cao cấp và nhân viên dưới quyền (Hofstede et al., 2010). Theo Park (2003), một điểm cần lưu ý ở chiều văn hóa này là sự chênh lệch về quyền lực không khuyến khích cấp dưới đặt câu hỏi cho cấp trên và do đó nó có khả năng làm tăng rủi ro lạm dụng quyền lực. Theo đó, nếu những người dưới quyền có hành động tố cáo đối với cấp trên thì bị cho là không trung thành và không được xã hội chấp nhận.

H3: Mức độ khoảng cách quyền lực trong văn hóa quốc gia của CEO càng cao, mức độ rủi ro phá sản ngân hàng càng cao

\section{Các biến, mô hình và dữ liệu}

\subsection{Biến đo lường rủi ro}

Chỉ số Z (Z-score): Theo Boyd, Graham, và Hewitt (1993), mức độ rủi ro phá sản của ngân hàng có thể được đo lường qua hai chỉ số: vốn chủ sở hữu trên tổng tài sản (CATA) và lợi nhuận trên tổng tài sản (ROA). Trong nghiên cứu này, chúng tôi định nghĩa ngân hàng sẽ phá sản nếu các khoản lỗ hiện tại vượt quá vốn $(\mathrm{ROA}+\mathrm{CATA} \leq 0)$. Boyd và cộng sự (1993) chứng minh rằng nếu ROA là biến ngẫu nhiên, có trung bình $\mu \mathrm{ROA}$ và phương sai $\sigma^{2} \mathrm{ROA}$ thì bất đẳng thức Bienaymé-Chebyshev cho phép chúng ta xác định được giới hạn trên của xác suất phá sản của ngân hàng như sau:

$$
\mathrm{p}(\mathrm{ROA} \leq-\mathrm{CATA}) \leq \mathrm{Z}^{-2}
$$

Trong đó, Z-score có mối quan hệ nghịch chiều với xác xuất phá sản ngân hàng. Khi Zscore cao thì xác suất phá sản ngân hàng thấp và ngược lại. Z-score được tính bằng đẳng thức:

$$
\mathrm{Z}=\frac{\operatorname{Mean}(\mathrm{ROA})+\mathrm{CATA}}{\sigma^{2}(\mathrm{ROA})}
$$




\subsection{Biến văn hóa}

Chúng tôi sử dụng các chiều văn hóa được phát triển bởi Giáo sư Hofstede (Hofstede, 2001) để xem xét sự khác biệt về văn hóa giữa các quốc gia. Giáo sư Hofstede bắt đầu quan tâm chủ đề văn hóa từ thập niên 1960. Sau đó, ông làm một cuộc điều tra với hàng ngàn nhân viên của IBM ở 53 quốc gia, trong suốt thời gian từ 1978 đến 1983. Thông qua quá trình phân tích dữ liệu, Giáo sư Hofstede nhận dạng 4 chiều văn hóa khác nhau bao gồm (1) chủ nghĩa cá nhân với chủ nghĩa tập thể (Individualism/Collectivism), (2) khoảng cách quyền lực (Power Distance), (3) tránh sự không chắc chắn (Uncertainty avoidance), (4) Nam tính/nữ tính (Masculinity/Femininity). Năm 1985, Giáo sư Hofstede cộng tác với Michael Bond, một người Canada, sống và làm việc tại Viễn Đông (Far East) từ năm 1971, để thực hiện lại nghiên cứu ở IBM bằng cách sử dụng bảng câu hỏi Chinese Value Survey (CSV). Theo Hofstede và Hofstede (2005), kết quả từ việc phân tích CSV giúp Giáo sư Hofstede nhận dạng chiều thứ năm của văn hóa, định hướng dài hạn / định hướng ngắn hạn (Long-term orientation/short-term normative orientation), bên cạnh 4 chiều ban đầu.

\subsection{Biến kiểm soát}

Trong nghiên cứu này, một số biến ở cấp độ ngân hàng được sử dụng để làm biến kiểm soát bao gồm tổng tài sản, cho vay ròng trên tổng tài sản, lợi nhuận bình quân trên tài sản $(R O A A)$ và các biến liên quan đến đặc tính của Hội đồng Quản trị như quy mô Hội đồng Quản trị, tỷ lệ nữ giới có mặt trong Hội đồng Quản trị và CEO kiêm nhiệm. Ngoài ra, chỉ số lạm phát và tốc độ tăng trưởng cũng được dùng để kiểm soát sự khác biệt ở cấp độ quốc gia.

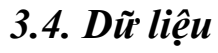

Dữ liệu dùng trong nghiên cứu này được lấy từ nhiều nguồn khác nhau như: cơ sở dữ liệu của $\mathrm{BANKSCOPE}$, báo cáo tài chính năm của các ngân hàng, Bloomberg, Reuters, Linkedin. Có thể nói rằng $\mathrm{BANKSCOPE}$ là một nguồn dữ liệu rộng lớn cho phép chúng tôi truy cập thông tin tài chính của hơn 50,000 ngân hàng trên khắp thế giới. Thông qua dữ liệu này, chúng tôi có thể thu thập được các chỉ số tài chính và các thông tin liên quan đến quản trị doanh nghiệp của ngân hàng như tên, vị trí công việc, giới tính, và quốc tịch của các thành viên trong Hội đồng Quản trị. Một điều hạn chế là BANKSCOPE không cho phép chúng tôi truy cập sự thay đổi trong cấu trúc Hội đồng Quản trị theo thời gian mặc dù những thông tin cần thiết đã có sẵn trên hệ thống. Điều này gây ra một chút vấn đề vì quốc tịch của $\mathrm{CEO}$ là một trong những biến quan trọng được sử dụng để xem xét ảnh hưởng văn hóa quốc gia của $\mathrm{CEO}$ lên rủi ro phá sản ngân hàng.

Để khắc phục khó khăn này, chúng tôi quyết định sử dụng những báo cáo tài chính được công bố hàng năm trên trang thông tin điện tử (website) của các ngân hàng để quan sát sự thay đổi trong cấu trúc của Hội đồng Quản trị. Trong trường hợp chúng tôi không thể thu thập thông tin quốc tịch của $\mathrm{CEO}$ từ $\mathrm{BANKSCOPE}$ và báo cáo hàng năm thì Bloomberg, Reuters and Linkedin là các nguồn thay thế. Để tránh làm thiên lệch kết quả, 2,500 ngân hàng thương mại được lọc ra từ 50,000 ngân hàng có trong cơ sở dữ liệu BANKSCOPE. Tiếp đến, các ngân hàng mà BANKSCOPE không báo cáo đầy đủ số liệu sẽ được loại ra. Cuối cùng, chúng tôi có một bảng dữ liệu không cân bằng có chứa thông tin của 395 CEO đến từ 20 nền văn hóa khác nhau. Những CEO này làm việc cho 237 ngân hàng thương mại ở 21 quốc gia ${ }^{1}$ khác nhau trong khoảng thời gian từ 2011 đến 2017.

\footnotetext{
1 Afghanistan, Armenia, Bahrain, Bangladesh, Bhutan, Brunei, Cambodia, China, India, Georgia, Israel, Jordan, Kuwait, Malaysia, Nepal, Oman, Pakistan, Qatar, Saudi Arabia, Thailand, United Arab Emirates.
} 


\subsection{Mô hình}

Dựa trên lý thuyết và dữ liệu có sẵn, mô hình chi tiết của chúng tôi được đề xuất như sau:

Bank's risk indicators $_{i j t}=\beta_{0}+\beta 1$ CEO's national culture ${ }_{i}+\beta 2$ BoDcharacteristics $_{i j t}+\beta 3$

Bank's characteristics ${ }_{i j t}+\beta 4$ Country's characteristics + bank $_{i}+y_{e a r_{t}}+\varepsilon_{i j t}$

Trong đó $\mathrm{i}, \mathrm{j}, \mathrm{t}$ lần lượt đề cập đến các ngân hàng, quốc gia và năm. Bank's risk indicators là chỉ số rủi ro phá sản ngân hàng (Z-score). CEO's national culture là biến văn hóa của CEO được định nghĩa theo lý thuyết chiều văn hóa Hofstede (khoảng cách quyền lực, tránh sự không chắc chắn, chủ nghĩa cá nhân với chủ nghĩa tập thể). Bankcharcteristics là tập hợp biến kiểm soát gồm quy mô ngân hàng (tổng tài sản), khả năng thanh khoản của ngân hàng (khoản vay ròng trên tổng tài sản), lợi nhuận bình quân trên tài sản $(R O A A)$. BoDcharacteristics là biến kiểm soát liên quan đến đặc tính của Hội đồng Quản trị như quy mô Hội đồng Quản trị, tỷ lệ nữ giới có mặt trong Hội đồng Quản trị và CEO kiêm nhiệm. Country's characteristics gồm các biến kiểm soát ở cấp độ quốc gia như tỷ lệ lạm phát và tốc độ tăng trưởng. Cuối cùng, Bank $\mathrm{k}_{\mathrm{i}}$ và year là những biến giả theo thời gian $t$ và ngân hàng $i$. $\varepsilon_{\mathrm{ijt}}$ là sai số.

\section{Kết quả chính và kiểm tra độ chắc chắn (Robustness test)}

\subsection{Thống kê mô tả}

Bảng 1 chứa thông tin thống kê mô tả các biến trong mô hình. Z-score có giá trị trung bình là 10 và độ lệch chuẩn là 9 . CEO kiêm nhiệm không phải là một hiện tượng phổ biến khi trung bình của biến ceoduality chỉ 0.08 . Ngoài ra, chúng tôi nhận thấy có sự thiên lệch về giới tính trong Hội đồng quản trị. Giá trị trung bình và độ lệch chuẩn của biến ceogender là 0.92 và 0.27 cho thấy hầu hết các CEO trong mẫu là nam giới. Tiếp theo, tỷ lệ trung bình của nữ giới có mặt trong hội đồng quản trị là $9.93 \%$. Điều này củng cố kết quả trước đó về sự hiện diện vượt trội của nam giới so với nữ giới trong Hội đồng Quản trị. Ngoài ra, thống kê mô tả còn cho thấy chỉ số văn hóa của Hofstede có một vài điều thú vị trong mẫu. Chúng tôi nhận thấy giá trị trung bình của chỉ số chủ nghĩa cá nhân $(I N D)$ ở mức tương đối thấp là 34 với độ lệch chuẩn là 20 . Ngoài ra, giá trị trung bình của chỉ số khoảng cách quyền lực (PDI) và chỉ số tránh sự không chắc chắn (UAI) lần lượt là 71 và 52.5 trong khi độ lệch chuẩn của chúng chỉ là 19.4 và 20.7. Điều này ám chỉ hầu hết các CEO trong mẫu đến từ những nền văn hóa có khoảng cách quyền lực lớn, ít chủ nghĩa cá nhân và không ưu thích rủi ro. Trong Bảng 2 , chúng tôi trình bày một ma trận tương quan giữa các biến. Chúng tôi thấy rằng hệ số tương quan giữa các biến rất thấp, dưới 0.3 trong hầu hết các trường hợp. Do đó, không có hiện tượng đa cộng tuyến trong mô hình. Chỉ một trường hợp cần chú ý là chiều văn hóa chủ nghĩa cá nhân (IND) có tương quan cao với khoảng cách quyền lực (PDI). Điều này ngụ ý IND và PDI nên được hồi quy riêng để tránh hiện tượng đa cộng tuyến có thể xảy ra.

\section{Bảng 1}

Thống kê mô tả

\begin{tabular}{|l|c|c|c|c|c|}
\hline \multicolumn{1}{|c|}{ Variable } & Obs & Mean & Std. Dev. & Min & Max \\
\hline Zscore & 1143 & 10 & 9 & -39 & 64 \\
\hline Totalass & 1143 & 91696 & 372558 & 44 & 4000000 \\
\hline Roaa & 1143 & 1 & 2 & -18 & 24 \\
\hline netloansto $\sim$ s & 1143 & 51 & 17 & 0 & 85 \\
\hline Boardsize & 1143 & 10 & 3 & 1 & 23 \\
\hline
\end{tabular}




\begin{tabular}{|l|c|c|c|c|c|}
\hline \multicolumn{1}{|c|}{ Variable } & Obs & Mean & Std. Dev. & Min & Max \\
\hline Ceoduality & 1143 & 0.08 & 0.27 & 0.00 & 1.00 \\
\hline Ceogender & 1143 & 0.92 & 0.27 & 0.00 & 1.00 \\
\hline Femalebod & 1143 & 9.93 & 12.65 & 0.00 & 100.00 \\
\hline CPI & 1143 & 3.82 & 2.80 & -1.40 & 11.92 \\
\hline Growth & 1143 & 4.61 & 2.32 & -4.71 & 13.38 \\
\hline Ind & 1143 & 34.0 & 20.3 & 14 & 91 \\
\hline Pdi & 1143 & 71.0 & 19.4 & 13 & 100 \\
\hline Mas & 1143 & 52.2 & 9.9 & 14 & 95 \\
\hline Uai & 1143 & 52.5 & 20.7 & 8 & 99 \\
\hline
\end{tabular}

Ghi chú: Zscore là Zscore index. Totalasset là tổng tài sản (mil USD), Roaa là lợi nhuận trên trung bình tổng tài sản (\%). Netloantotalasset cho vay ròng trên tổng tài sản (\%). Boardsize là số lượng thành viên trong Hội đồng Quản trị. Ceoduality là biến giả có giá trị bằng 1 nếu $\mathrm{CEO}$ đồng thời là chủ tịch Hội đồng Quản trị và bằng 0 trong trường hợp ngược lại. Ceogender đo lường giới tính của $\mathrm{CEO}$, có giá trị là 1 nếu $\mathrm{CEO}$ là nam và 0 trong trường hợp ngược lại, FemaleBOD Tỷ lệ phần trăm của giám đốc nữ trong Hội đồng Quản trị $(\%)$. CPI là chỉ số lạm phát (\%). Growth là tốc độ tăng trưởng (\%). PDI là chỉ số khoảng cách quyền lực, IND là chỉ số chủ nghĩa cá nhân và chủ nghĩa tập thể, UAI chỉ số hạn chế không chắc chắn

Nguồn: Bankscope và báo cáo tài chính 


\section{Bảng 2}

Sự tương quan giữa các biến

\begin{tabular}{|c|c|c|c|c|c|c|c|c|c|c|c|c|c|c|}
\hline & \begin{tabular}{l}
0 \\
\multirow{3}{*}{} \\
\multirow{2}{*}{}
\end{tabular} & $\frac{\mathfrak{2}}{\mathfrak{s}}$ & $\$$ & 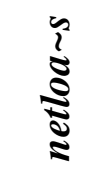 & 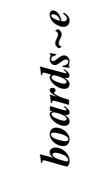 & 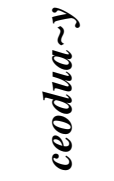 & \begin{tabular}{l}
$i$ \\
\multirow{5}{5}{} \\
8 \\
8 \\
8
\end{tabular} & 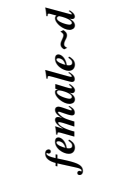 & $\bar{v}$ & $\frac{\tilde{t}}{0}$ & $\tilde{\Sigma}$ & $\mathbb{\Xi}$ & $\stackrel{\Xi}{\Xi}$ & $\mathbb{3}$ \\
\hline zscore & 1.00 & & & & & & & & & & & & & \\
\hline totalassets & -0.12 & 1.00 & & & & & & & & & & & & \\
\hline roaa & 0.30 & -0.01 & 1.00 & & & & & & & & & & & \\
\hline netloansto $\sim S$ & -0.43 & 0.01 & -0.09 & 1.00 & & & & & & & & & & \\
\hline boardsize & -0.14 & -0.11 & 0.00 & 0.34 & 1.00 & & & & & & & & & \\
\hline ceoduality & -0.12 & -0.03 & -0.13 & 0.08 & 0.10 & 1.00 & & & & & & & & \\
\hline ceogender & -0.05 & 0.04 & -0.01 & 0.10 & -0.01 & -0.02 & 1.00 & & & & & & & \\
\hline femalebod & -0.03 & 0.11 & 0.00 & -0.07 & 0.01 & -0.04 & -0.20 & 1.00 & & & & & & \\
\hline$C P I$ & -0.23 & 0.04 & -0.08 & 0.02 & 0.05 & 0.20 & 0.06 & -0.02 & 1.00 & & & & & \\
\hline growth & -0.19 & -0.12 & -0.12 & 0.17 & 0.11 & 0.17 & 0.00 & -0.02 & 0.23 & 1.00 & & & & \\
\hline$p d i$ & 0.17 & 0.07 & 0.04 & -0.10 & -0.15 & 0.06 & 0.07 & -0.03 & 0.06 & 0.13 & 1.00 & & & \\
\hline ind & -0.06 & -0.11 & -0.04 & 0.23 & 0.11 & 0.11 & -0.01 & -0.04 & -0.09 & 0.09 & -0.48 & 1.00 & & \\
\hline mas & -0.16 & 0.24 & -0.13 & -0.03 & -0.10 & 0.04 & 0.11 & 0.11 & 0.16 & 0.10 & 0.09 & 0.16 & 1.00 & \\
\hline uai & 0.22 & -0.20 & 0.06 & 0.03 & 0.17 & -0.09 & 0.03 & -0.22 & -0.13 & -0.25 & -0.17 & -0.13 & -0.27 & 1.00 \\
\hline
\end{tabular}

Nguồn: Kết quả phân tích dữ liệu của nhóm nghiên cứu 


\subsection{Kết quả chính}

Kết quả chính của nghiên cứu này được trình bày trong Bảng 3 . Mô hình 1 được dùng để kiểm tra giả thuyết văn hóa cá nhân có làm tăng rủi ro ngân hàng hay không. Bằng chứng cho thấy hệ số $I N D$ dương và có ý nghĩa thống kê với $Z$-score. Kết quả này cho thấy các $C E O$ đến từ nền văn hóa cá nhân không những không làm tăng rủi ro ngân hàng như dự đoán trước đó mà ngược lại còn quản lý ngân hàng theo hướng ít rủi ro hơn. Vậy chúng ta giải thích như thế nào về kết quả trái ngược này? Tham khảo lại các nghiên cứu về văn hóa gần đây, chúng tôi nhận thấy rằng sẽ rất hợp lý khi giả định CEO có văn hóa cá nhân mạnh sẽ hành xử theo hướng tối đa hóa lợi ích của mình, và do đó làm gia tăng rủi ro của ngân hàng. Tuy nhiên, các nghiên cứu đa văn hóa của Redding và Wong (1986) và Waterman (1988) cho thấy giả thuyết nêu trên có thể không chính xác vì các quy tắc hành xử (norms) khác nhau giữa xã hội tập thể và cá nhân. Theo Redding và Wong (1986), nguyên tắc hành xử trong xã hội tập thể như ở Trung Quốc cho phép ưu ái những người trong nhóm (e.g., những người trong gia đình, bạn bè, người thân) trong khi từ chối yêu cầu tương tự từ những thành viên ngoài nhóm (người sống cùng thành phố, hoặc quốc gia). Ngược lại, trong xã hội cá nhân như Mỹ và Châu Âu, đối xử không công bằng với người khác là phạm pháp, thay vào đó đối xử bình đẳng với tất cả mọi người là tiêu chuẩn được chấp nhận rộng rãi (Waterman, 1988). Do vậy, lập luận này đưa đến một nhận định là sự khác biệt trong cách đối xử giữa thành viên trong và ngoài nhóm mang đến những kết quả rất khác nhau. Trong bối cảnh của ngân hàng, mức độ rủi ro phá sản ngân hàng sẽ gia tăng khi CEO theo văn hóa tập thể ưu tiên thỏa mãn nhu cầu của người trong nhóm bất chấp rủi ro tiềm ẩn có thể ảnh hưởng đến lợi ích của ngân hàng. Chen, Peng, và Saparito (2002) tin rằng hiểu các quy tắc ứng xử giữa người và người là chìa khóa để giải thích tại sao một $\mathrm{CEO}$ theo chủ nghĩa tập thể lại gặp nhiều rủi ro hơn một CEO theo chủ nghĩa cá nhân.

Mô hình 2 trình bày kết quả hồi quy về mối quan hệ giữa khoảng cách quyền lực của CEO và rủi ro phá sản ngân hàng. Kết quả cho thấy hệ số của PDI nghịch biến và mức ý nghĩa dưới $10 \%$. Điều này khẳng định giả thuyết rằng khoảng cách quyền lực trong văn hóa quốc gia của $\mathrm{CEO}$ càng cao thì mức độ rủi ro phá sản ngân hàng cũng ở mức cao. Trong mô hình 3 , chỉ số hạn chế không chắc chắn được dùng để kiểm tra mối quan hệ giữa thái độ chấp nhận rủi ro với rủi ro phá sản ngân hàng. Kết quả cho thấy không có mối quan hệ thống kê để xác nhận mối quan hệ này khi hệ số của $U A I$ là dương nhưng không có ý nghĩa thống kê. Điều này xác nhận văn hóa hạn chế rủi ro của $\mathrm{CEO}$ không có tác động đến rủi ro ngân hàng.

\section{Bảng 3}

Kết quả phân tích hồi quy

\section{VARIABLES}

Totalassets

Totalassets

Roaa

Netloantotalasset

Boardsize

\section{Z-score}

(1)

$-6.97 \mathrm{e}-07$

(2.03e-06)

$1.300 * * *$

(0.386)

$-0.0227$

(0.0406)

$-0.0762$
Z-score

(2)

$-6.49 \mathrm{e}-07$

(2.01e-06)

1.298***

$-0.0211$

(0.0406)

$-0.0821$
Z-score

(3)

$-5.87 \mathrm{e}-07$

(2.03e-06)

$1.288 * * *$

$-0.0208$

(0.0405) 


\begin{tabular}{|c|c|c|c|}
\hline VARIABLES & $\begin{array}{c}Z \text {-score } \\
\text { (1) }\end{array}$ & $\begin{array}{c}Z \text {-score } \\
\text { (2) }\end{array}$ & $\begin{array}{c}Z \text {-score } \\
\text { (3) }\end{array}$ \\
\hline & $(0.0603)$ & $(0.0605)$ & $(0.0608)$ \\
\hline \multirow[t]{2}{*}{ Ceoduality } & 0.460 & 0.469 & 0.466 \\
\hline & $(0.645)$ & $(0.647)$ & $(0.642)$ \\
\hline \multirow[t]{2}{*}{ Ceogender } & 0.524 & 0.497 & 0.565 \\
\hline & $(0.556)$ & $(0.560)$ & $(0.566)$ \\
\hline \multirow[t]{2}{*}{ FemaleBOD } & 0.0197 & 0.0181 & 0.0210 \\
\hline & $(0.0187)$ & $(0.0185)$ & $(0.0181)$ \\
\hline \multirow[t]{2}{*}{$C P I$} & 0.0280 & 0.0240 & 0.0162 \\
\hline & $(0.0513)$ & $(0.0518)$ & $(0.0530)$ \\
\hline \multirow[t]{2}{*}{ Growth } & -0.226 & -0.225 & -0.217 \\
\hline & $(0.234)$ & $(0.233)$ & $(0.232)$ \\
\hline \multirow[t]{2}{*}{ IND } & $0.0379 *$ & & \\
\hline & $(0.0196)$ & & \\
\hline \multirow[t]{2}{*}{ PDI } & & $-0.0448 *$ & \\
\hline & & $(0.0243)$ & \\
\hline \multirow[t]{2}{*}{$\boldsymbol{U A I}$} & & & -0.0106 \\
\hline & & & $(0.0228)$ \\
\hline \multirow[t]{2}{*}{ Constant } & $7.044 * * *$ & $12.08 * * *$ & $8.790 * * *$ \\
\hline & $(1.792)$ & $(3.793)$ & $(3.367)$ \\
\hline Observations & 1,143 & 1,143 & 1,143 \\
\hline Number of id & 237 & 237 & 237 \\
\hline Bank FE & YES & YES & YES \\
\hline Year FE & YES & YES & YES \\
\hline
\end{tabular}

Ghi chú: Robust standard errors in parentheses

$* * * \mathrm{p}<0.01, * * \mathrm{p}<0.05, * \mathrm{p}<0.1$

Zscore là Zscore index. Totalasset là tổng tài sản (mil USD), Roaa là lợi nhuận trên trung bình tổng tài sản (\%). Netloantotalasset cho vay ròng trên tổng tài sản (\%). Boardsize là số lượng thành viên trong Hội đồng Quản trị. Ceoduality là biến giả có giá trị bằng 1 nếu $\mathrm{CEO}$ đồng thời là chủ tịch Hội đồng Quản trị và bằng 0 trong trường hợp ngược lại. Ceogender đo lường giới tính của $\mathrm{CEO}$, có giá trị là 1 nếu $\mathrm{CEO}$ là nam và 0 trong trường hợp ngược lại, FemaleBOD Tỷ lệ phần trăm của giám đốc nữ trong Hội đồng Quản trị (\%). CPI là chỉ số lạm phát (\%). Growth là tốc độ tăng trưởng (\%). PDI là chỉ số khoảng cách quyền lực, IND là chỉ số chủ nghĩa cá nhân và chủ nghĩa tập thể, UAI chỉ số hạn chế không chắc chắn.

Nguồn: Kết quả phân tích dữ liệu của nhóm nghiên cứu 


\subsection{Kiểm tra độ chắc chắn (Robustness test)}

Một vấn đề tiềm ẩn có thể dẫn tới sai lệch trong kết quả là hiện tượng nội sinh (endogeneity). Wooldridge (2002) chỉ ra 3 nguồn chính dẫn đến hiện tượng nội sinh bao gồm quan hệ nhân quả ngược giữa biến chính (Z-score) và biến giải thích (các chiều văn hóa), thiếu biến và sai sót đo lường. Liên quan đến quan hệ nhân quả ngược, chúng tôi tin rằng đó không phải là mối quan tâm chính đối với hiện tượng nội sinh. Lí do là phải mất nhiều thế hệ để thay đổi các giá trị văn hóa, do đó chúng tôi không kỳ vọng xảy ra mối quan hệ qua lại giữa rủi ro ngân hàng và các chiều văn hóa. Nhận định này được củng cố trong nghiên cứu của Hofstede và cộng sự (2010). Trong tác phẩm này, tác giả báo cáo có ít nhất 6 nghiên cứu được thực hiện từ năm 1990 đến 2002 nhằm mục đích mô phỏng những gì mà Hofstede làm vào thập niên 1960. Kết quả là chiều văn hóa của Hofstede gần như không có sự thay đổi từ khi ông phát hiện ra.

Để xử lý hai nguồn nội sinh khác, phương pháp hồi quy bình phương bé nhất (2SLS) với biến công cụ dược áp dụng. Wooldridge (2002) chỉ ra điểm quan trọng trong cách tiếp cận 2SLS là các biến công cụ cần tương quan với các biến nội sinh (Chỉ số khoảng cách quyền lực) nhưng không liên quan với Z-score. Trong nghiên cứu này, chúng tôi học tập cách tiếp cận của Ashraf và cộng sự (2016) khi sử dụng Chỉ số Lan truyền Dịch bệnh ${ }^{2}$ (Diseases Prevalence Index), được phát triển bởi Murray và Schaller (2010) làm công cụ đo lường Chỉ số Khoảng cách Quyền lực. Theo Fincher, Thornhill, Murray, và Schaller (2008), các cá nhân của văn hóa tập thể có xu hướng ngại tiếp xúc với các thành viên bên ngoài nhóm của họ. Điều này cũng có nghĩa là hạn chế luôn việc tiêu thụ những thực phẩm lạ, một nguồn quan trọng để cải thiện hệ thống đề kháng của cơ thể (Murray \& Schaller, 2010). Do đó, chúng ta kỳ vọng Chỉ số Lan truyền Dịch bệnh sẽ có tương quan thuận với văn hóa tập thể. Ngoài ra, Hofstede và cộng sự (2010) nhận thấy rằng ở những xã hội theo văn hóa tập thể, khoảng cách quyền lực thường được ghi nhận rất cao. Điều này là do các thành viên phải thể hiện sự tôn trọng và phục tùng quyết định của cả nhóm cũng như trưởng nhóm. Vì vậy, chúng tôi kỳ vọng Chỉ số Lan truyền Dịch bệnh có tương quan dương với Chỉ số Khoảng cách Quyền lực và không có bất kỳ ảnh hưởng nào lên rủi ro ngân hàng.

Bảng 4 là kết quả hồi quy của các biến công cụ. Trong Bảng 4 , chúng tôi tìm thấy hệ số của Chỉ số Lan truyền Dịch bệnh tương quan thuận với PDI và có ý nghĩa thống kê ở mức $1 \%$. Điểm cần lưu ý là giá trị hệ số của Chỉ số Lan truyền Dịch bệnh khá cao. Điều này cho thấy các biến công cụ thỏa mãn điều kiện cần trong giai đoạn đầu của mô hình hồi quy 2SLS. Trong giai đoạn thứ 2 , các hệ số PDI cho các dấu hiệu như mong đợi. PDI có mối quan hệ nghịch chiều với Z-score với mức ý nghĩa thống kê $1 \%$. Điều này xác nhận không có hiện tượng nội sinh trong các mô hình.

\section{Bảng 4}

Kết quả kiểm định vấn đề nội sinh với mô hình Bình phương Hai giai Đoạn (2SLS)

(1)

VARIABLES

PDI

(Giai đoạn 1)

Z-score (Giai đoạn 2)

Totalassets

$\begin{array}{ll}1.60 \mathrm{e}-06^{* *} & -1.99 \mathrm{e}-07 \\ (6.74 \mathrm{e}-07) & (1.33 \mathrm{e}-06)\end{array}$

\footnotetext{
${ }^{2}$ Định nghĩa chi tiết được trình bày trong Bảng 5 .
} 
VARIABLES

Roaa

Netloantotalasset

Boardsize

Ceoduality

Ceogender

FemaleBOD

CPI

Growth

Diseases Prevalence Index

PDI

Constant

$74.56^{* * * *}$

R-square
(3.377)

1,113

0.24

(2)

Z-score (Giai đoạn 2)

$-0.285^{* * *}$

(0.0340)

$1.452 * * *$

$(0.239)$

$-0.444 * *$

(0.194)

2.087

(1.750)

2.430

(1.745)

$-0.0440$

$(0.0345)$

$-0.459 * * *$

(0.162)

$0.544^{*}$

$(0.304)$

7.07***

(1.58)

$-0.57 * * *$

(-0.15)

$64.70 * * *$

1,113

0.17

Ghi chú: Robust standard errors in parentheses

$* * * \mathrm{p}<0.01, * * \mathrm{p}<0.05, * \mathrm{p}<0.1$

Bảng này hiển thị kết quả của hồi quy mô hình Bình phương Tối thiểu Hai giai đoạn. Mô hình 1 chứa kết quả hồi quy giai đoạn đầu với các biến công cụ. Chúng tôi sử dụng Chỉ số Lan truyền Dịch bệnh ở các khu vực địa chính trị khác nhau trong lịch sử. Chúng tôi thấy rằng các hệ số của Chỉ số Lan truyền Dịch bệnh có ý nghĩa thống kê và dấu như kỳ vọng. Hơn nữa, độ lớn của các hệ số là khá lớn. Điều này chỉ ra rằng Chỉ số Lan truyền Dịch bệnh là một biến công cụ tốt. Mô hình 2 trình bày kết quả trong giai đoạn 2 . Chúng tôi nhận thấy rằng các hệ số của PDI vẫn phù hợp với các bằng chứng trong hồi quy chính. Điều này xác nhận rằng không có hiện tượng nội sinh trong mô hình

Nguồn: Kết quả phân tích dữ liệu của nhóm nghiên cứu 


\section{Kết luận}

Đã có nhiều nghiên cứu thực nghiệm đã xác nhận tồn tại mối quan hệ giữa văn hóa và rủi ro phá sản ngân hàng. Liên quan đến chủ đề này, xu hướng chủ đạo thường phân tích mối quan hệ này ở cấp độ quốc gia hơn là cấp độ cá nhân. Trong nghiên cứu này, chúng tôi bổ sung các cơ sở lý thuyết này bằng cách cung cấp những bằng chứng thực nghiệm về ảnh hưởng của văn hóa quốc gia của $\mathrm{CEO}$ lên rủi ro phá sản ngân hàng. Chúng tôi tìm thấy rủi ro phá sản ngân hàng có mối tương quan đồng biến với những $\mathrm{CEO}$ có điểm số cao khoảng cách quyền lực.

Các phát hiện trong nghiên cứu này mang lại một vài gợi ý cho chính sách quản lý rủi ro của ngân hàng. Đầu tiên, có thể sử dụng văn hóa như một lá chắn để bảo vệ các ngân hàng tránh khỏi hành vi gây rủi ro. Các ngân hàng, đặc biệt ở các nước đang phát triển có thể thuê những CEO đến từ xã hội có ít có khoảng cách quyền lực như là một phương pháp làm giảm rủi ro phá sản ngân hàng. Ngoài ra, chúng tôi khuyến nghị cần có những nghiên cứu tiếp theo thực hiện ở những quốc gia như Mỹ và Châu Âu bởi lẽ ở các quốc gia này $\mathrm{CEO}$ của ngân hàng thông thường là những $\mathrm{CEO}$ theo văn hóa cá nhân. Vì vậy chúng ta có thể kỳ vọng rằng rủi ro sẽ thấp ở các nước phương tây. Thế nhưng, thực tế lại cho thấy ngược lại các ngân hàng của Mỹ và Châu Âu có những giai đoạn cực kỳ rủi ro, đặc biệt trong giai đoạn khủng hoảng ngân hàng 2007 tại Mỹ và khủng hoảng nợ công ở Châu Âu.

\section{Bảng 5}

Định nghĩa các biến và nguồn dữ liệu

\begin{tabular}{|c|c|c|}
\hline Tên biến & Định nghĩa & Nguồn \\
\hline Zscore & $\begin{array}{l}\text { Z-score } \equiv(\mathrm{CATA}+\mathrm{Mean}(\mathrm{ROA})) / \sigma 2(\mathrm{ROA}), \mathrm{CATA} \text { là tỷ số } \\
\text { vốn chủ sở hữu/ tổng tài sản, ROA Lợi nhuận trên trung bình } \\
\text { tổng tài sản. }\end{array}$ & \multirow{4}{*}{ Bankscope } \\
\hline Totalassets & Tổng tài sản (mil USD). & \\
\hline Roaa & Lợi nhuận trên trung bình tổng tài sản (\%). & \\
\hline Netloanstotalassets & Cho vay ròng / Tổng tài sản (\%). & \\
\hline Boardsize & Số lượng thành viên trong Hội đồng Quản trị & \multirow{4}{*}{$\begin{array}{l}\text { Bank's } \\
\text { annual report }\end{array}$} \\
\hline Ceoduality & $\begin{array}{l}\text { Biến giả có giá trị bằng } 1 \text { nếu } \mathrm{CEO} \text { đồng thời là chủ tịch Hội } \\
\text { đồng Quản trị và bằng } 0 \text { trong trường hợp ngược lại }\end{array}$ & \\
\hline Ceogender & $\begin{array}{l}\text { Giới tính của CEO, có giá trị là } 1 \text { nếu CEO là nam và } 0 \text { trong } \\
\text { trường hợp ngược lại. }\end{array}$ & \\
\hline FemaleBOD & $\begin{array}{l}\text { Tỷ lệ phần trăm của giám đốc nữ trong Hội đồng Quản trị } \\
(\%) \text {. }\end{array}$ & \\
\hline PDI & $\begin{array}{l}\text { Chỉ số khoảng cách quyền lực là mức độ mà các thành viên ít } \\
\text { mạnh hơn trong các tổ chức (gia đình, trường học, tổ chức) } \\
\text { trong một xã hội mong đợi và chấp nhận rằng quyền lực được } \\
\text { chia sẻ không đồng đều. Chỉ số này nằm trong phạm vi giá trị } \\
\text { từ } 0 \text { đến } 100 \text {. }\end{array}$ & $\begin{array}{l}\text { Hofstede } \\
(2001)\end{array}$ \\
\hline
\end{tabular}




\begin{tabular}{|c|c|c|}
\hline Tên biến & Định nghĩa & Nguồn \\
\hline IND & $\begin{array}{l}\text { Chỉ số chủ nghĩa cá nhân và chủ nghĩa tập thể đề cập đến mức } \\
\text { độ mà mọi người được kỳ vọng sẽ hành xử theo lợi ích cá } \\
\text { nhân hoặc nhóm. Chỉ số này nằm trong phạm vi giá trị từ } 0 \\
\text { đến } 100 \text {. }\end{array}$ & \\
\hline UAI & $\begin{array}{l}\text { Chỉ số tránh sự không chắc chắn là mức độ mà các thành viên } \\
\text { của một nền văn hóa cảm thấy không thoải mái bởi tương lai } \\
\text { không thể đoán trước. Chỉ số này nằm trong phạm vi giá trị } \\
\text { từ } 0 \text { đến } 100 \text {. }\end{array}$ & \\
\hline $\begin{array}{l}\text { Diseases } \\
\text { Prevalence Index }\end{array}$ & $\begin{array}{l}\text { Chỉ số Lan truyền Dịch bệnh ghi nhận tần suất xuất hiện chín bệnh } \\
\text { truyền nhiếm ở } 160 \text { khu vực địa chính trị trong lịch sử bao gồm sốt } \\
\text { rét (malaria), bệnh phong (leprosy), bệnh leishmanias, bệnh sán } \\
\text { máng (schistosome), bệnh ngủ Châu Phi (trypanosome), sốt phát } \\
\text { ban (typhus), bệnh giun chỉ (filariae), sốt xuất huyết (dengue) và } \\
\text { bệnh lao (tuberculosis). Murray và Schaller (2010) sử dụng thang } \\
\text { mã hóa } 4 \text { bậc để xác định mức độ phổ biến bệnh cho từng bệnh: } 0 \\
\text { = hoàn toàn không có hoặc không có báo cáo, } 1 \text { = hiếm khi được } \\
\text { báo cáo, } 2=\text { báo cáo lẻ tẻ hoặc vừa phải, } 3=\text { ở mức độ nghiêm } \\
\text { trọng hoặc mức độ dịch cấp độ ít nhất một lần. }\end{array}$ & $\begin{array}{l}\text { Murray và } \\
\text { Schaller } \\
(2010)\end{array}$ \\
\hline CPI & Chỉ số lạm phát (\%) & $\begin{array}{c}\text { World } \\
\text { Development } \\
\text { Indicator }\end{array}$ \\
\hline Growth & Tốc độ tăng trưởng (\%GDP) & $\begin{array}{c}\text { World } \\
\text { Development } \\
\text { Indicator }\end{array}$ \\
\hline
\end{tabular}

Nguồn: Kết quả phân tích dữ liệu của nhóm nghiên cứu

\section{Tài liệu tham khảo}

Ashraf, B. N., Zheng, C., \& Arshad, S. (2016). Effects of national culture on bank risk-taking behavior. Research in International Business and Finance, 37, 309-326.

Boateng, A., Wang, Y., Ntim, C., \& Glaister, K. W. (2020). National culture, corporate governance and corruption: A cross - country analysis. Retrieved December 15, 2020, from https://www.researchgate.net/publication/342318507_National_Culture_Corporate_Gover nance_and_Corruption_A_Cross-country_Analysis

Boyd, J. H., Graham, S. L., \& Hewitt, R. S. (1993). Bank holding company mergers with nonbank financial firms: Effects on the risk of failure. Journal of Banking and Finance, 17(1), 43-63.

Bushman, R. M., Davidson, R. H., Dey, A., \& Smith, A. (2015). Bank CEO materialism, corporate culture, and risk. Journal of Accounting and Economics, 65(1), 191-220.

Bussoli, C. (2017). Influence of national culture on bank risk-taking in the European system. In Risk Culture in Banking (pp. 215-239). Berlin, Germany: Springer. 
Chen, C. C., Peng, M. W., \& Saparito, P. A. (2002). Individualism, collectivism, and opportunism: A cultural perspective on transaction cost economics. Journal of Management, 28(4), 567-583.

Fincher, C. L., Thornhill, R., Murray, D. R., \& Schaller, M. (2008). Pathogen prevalence predicts human cross-cultural variability in individualism/collectivism. Proceedings of the Royal Society of London B: Biological Sciences, 275(1640), 1279-1285.

Hofstede, G. (1983). National cultures in four dimensions: A research-based theory of cultural differences among nations. International Studies of Management \& Organization, 13(1/2), 46-74.

Hofstede, G. (2001). Culture's consequences: Comparing values, behaviors, institutions and organizations across nations. Thousand Oaks, CA: Sage publications.

Hofstede, G., \& Hofstede, G. (2005). Culture and organizations: Software of the mind. New York, NY: McGraw-Hill.

Hofstede, G., Hofstede, G. J., \& Minkow, M. (2010). Organizations and cultures: Software of the mind. New York, NY: McGraw-Hill.

Kanagaretnam, K., Lim, C. Y., \& Lobo, G. J. (2013). Influence of national culture on accounting conservatism and risk-taking in the banking industry. The Accounting Review, 89(3), 1115-1149.

Kwok, C. C., \& Tadesse, S. (2006). National culture and financial systems. Journal of International Business Studies, 37(2), 227-247.

Markus, H. R., \& Kitayama, S. (1991). Culture and the self: Implications for cognition, emotion, and motivation. Psychological Review, 98(2), 224-253.

Mervelskemper, L., Möller, R., \& Schumacher, S. (2018). How does corporate culture affect banks' risk-taking? Evidence from the European banking sector. Retrieved March 10, 2020, from https://www.semanticscholar.org/paper/How-does-Corporate-Culture-affect-Banks$\%$ E2\%80\%99-Evidence-MervelskemperM\%C3\%B61ler/504547c8d65464c9f43887e57d9d8ecee0784e4f

Mourouzidou-Damtsa, S., Milidonis, A., \& Stathopoulos, K. (2017). National culture and bank risk-taking. Journal of Financial Stability, 40, 132-143.

Murray, D. R., \& Schaller, M. (2010). Historical prevalence of infectious diseases within 230 geopolitical regions: A tool for investigating origins of culture. Journal of Cross-Cultural Psychology, 41(1), 99-108.

Nguyen, D. D., Nguyen, L., \& Sila, V. (2018). Does corporate culture affect bank risk-taking? Evidence from loan-level data. British Journal of Management, 30(1), 106-133.

Nilsen, J. L. (2016). A grounded theory study: Can a new CEO proactively evolve and manage organizational culture? (Doctoral dissertation). Benedictine University, Lisle, IL.

O'Reilly, C. A., Caldwell, D. F., Chatman, J. A., \& Doerr, B. (2014). The promise and problems of organizational culture: CEO personality, culture, and firm performance. Group \& Organization Management, 39(6), 595-625.

Park, H. (2003). Determinants of corruption: A cross-national analysis. Multinational Business Review, 11(2), 29-48. 
López, J. A. P., \& Santos, J. M. S. (2014). Does corruption have social roots? The role of culture and social capital. Journal of Business Ethics, 122(4), 697-708. doi:10.1007/s10551-0131789-9

Pillay, S., \& Dorasamy, N. (2010). Linking cultural dimensions with the nature of corruption: An institutional theory perspective. International Journal of Cross Cultural Management, 10(3), 363-378.

Shao, L., Kwok, C. C., \& Guedhami, O. (2010). National culture and dividend policy. Journal of International Business Studies, 41(8), 1391-1414.

Shupp, R. S., \& Williams, A. W. (2008). Risk preference differentials of small groups and individuals. The Economic Journal, 118(525), 258-283.

Redding, G., \& Wong, G. Y. (1986). The psychology of Chinese organizational behaviour. Oxford, UK: Oxford University Press.

Waterman, A. S. (1988). Psychological individualism and organizational functioning: A costbenefit analysis. In K. Kolenda (Ed.), Organizations and ethical individualism (pp. 19-46). County Mayo, Ireland: Praeger.

Wooldridge, J. M. (2002). Econometric analysis of cross section and panel data. Cambridge, MA: MIT Press.

Zheng, X. (2012). Two essays on culture and finance. (Doctoral dissertation). University of South Carolina, Columbia, SC. 